\title{
Endomorphin-1: Induction of Motor Behavior and Lack of Receptor Desensitization
}

\author{
Arpesh Mehta, ${ }^{1}$ George Bot, ${ }^{2}$ Terry Reisine, ${ }^{2}$ and Marie-Françoise Chesselet ${ }^{1}$ \\ ${ }^{1}$ Department of Neurology, University of California, Los Angeles School of Medicine, Los Angeles, California 90095, and \\ 2Department of Pharmacology, University of Pennsylvania School of Medicine, Philadelphia, Pennsylvania 19104
}

The endomorphins are recently discovered endogenous agonists for the $\mu$-opioid receptor (Zadina et al., 1997). Endomorphins produce analgesia; however, their role in other brain functions has not been elucidated. We have investigated the behavioral effects of endomorphin-1 in the globus pallidus, a brain region that is rich in $\mu$-opioid receptors and involved in motor control. Bilateral administration of endomorphin-1 in the globus pallidus of rats induced orofacial dyskinesia. This effect was dose-dependent and at the highest dose tested (18 pmol per side) was sustained during the 60 min of observation, indicating that endomorphin-1 does not induce rapid desensitization of this motor response. In agreement with a lack of desensitization of $\mu$-opioid receptors, $3 \mathrm{hr}$ of continuous exposure of the cloned $\mu$ receptor to endomorphin-1 did not dimin- ish the subsequent ability of the agonist to inhibit adenylate cyclase activity in cells expressing the cloned $\mu$-opioid receptor. Confirming the involvement of $\mu$-opioid receptors, the behavioral effect of endomorphin-1 in the globus pallidus was blocked by the opioid antagonist naloxone and the $\mu$-selective peptide antagonist $\mathrm{Cys}^{2}-\mathrm{Tyr}^{3}-\mathrm{Orn}^{5}-\mathrm{Pen}^{7}$ amide (CTOP). Furthermore, the selective $\mu$ receptor agonist $\left[\mathrm{D}-\mathrm{Ala}^{2}-\mathrm{N}-\mathrm{Me}-\mathrm{Phe}^{4}-\right.$ Glycol $^{5}$ ]-enkephalin (DAMGO) also stimulated orofacial dyskinesia when infused into the globus pallidus, albeit transiently. Our findings suggest that endogenous $\mu$ agonists may play a role in hyperkinetic movement disorders by inducing sustained activation of pallidal opioid receptors.

Key words: $\mu$-opioid receptors; dyskinesia; globus pallidus; cAMP; adenylate cyclase; movement disorders
Endomorphin-1 (Tyr-Pro-Trp-Phe- $\mathrm{NH}_{2}$ ) and endomorphin-2 (Tyr-Pro-Phe-Phe- $\mathrm{NH}_{2}$ ) are newly discovered endogenous opioid peptides that bind with high affinity to $\mu$-opioid receptors (Zadina et al., 1997). These peptides have little, if any, affinity for $\delta$ - or $\kappa$-opioid receptors (Zadina et al., 1997). The selectivity of the endomorphins for $\mu$-opioid receptors distinguishes these peptides from other endogenous opiates, such as the enkephalins and endorphins, which bind potently to $\delta$ - as well as $\mu$-opioid receptors, and dynorphin $\mathrm{A}$, which has relatively little affinity for $\mu$-opioid receptors (Raynor et al., 1994). Immunoreactivity for the endomorphins has been found in brain regions with high expression of $\mu$-opioid receptors (Zadina et al., 1997; MartinSchild et al., 1999; Pierce and Wessendorf, 2000). The high specificity of the endomorphins for $\mu$-opioid receptors and the colocalization of the peptide with the receptor have led Zadina et al. (1997) to propose that endomorphins are the endogenous transmitters for the $\mu$-opioid receptor.

The $\mu$-opioid receptor has clearly been shown to mediate analgesia (Massotte and Kieffer, 1998). However, the receptor is also expressed in brain regions not directly involved in analgesic circuits. In particular, it is highly expressed in the basal ganglia (Delfs et al., 1994; Peckys and Landwehrmeyer, 1999), a group of subcortical structures that play a critical role in the control of movement. Dysfunction of the basal ganglia resulting from specific degeneration of neurons, as in Parkinson's and Huntington's

Received Dec. 21, 2000; revised March 13, 2001; accepted March 22, 2001.

This work was supported by United States Public Health Service Grant MH44894. We thank Dr. Murray Goodman, University of California, San Diego, for the generous gift of endomorphin-1.

Correspondence should be addressed to Dr. Marie-Françoise Chesselet, Department of Neurology, UCLA School of Medicine, 710 Westwood Plaza, Los Angeles, CA 90095. E-mail: mchessel@ucla.edu.

Copyright (C) 2001 Society for Neuroscience 0270-6474/01/214436-07\$15.00/0 diseases, or from the administration of pharmacological agents leads to severe motor disorders (Albin et al., 1989; Chesselet and Delfs, 1996). A growing body of evidence suggests a role for endogenous opiates in the development of movement disorders. For example, altered opioid transmission in the basal ganglia has been implicated in Parkinson's disease (Sandyk, 1985; Gerfen et al., 1991), Huntington's disease (Sandyk, 1985; Albin et al., 1991), and tardive dyskinesia (Sabol et al., 1983; Tang et al., 1983; Sandyk, 1985). The latter are involuntary abnormal orofacial movements that may follow chronic administration of dopaminergic antagonists (neuroleptics) used to treat schizophrenia (Tarsy and Baldessarini, 1984).

Within the basal ganglia, a subpopulation of neurons of the globus pallidus (external pallidum in primates) expresses particularly high levels of $\mu$-opioid receptor mRNA (Delfs et al., 1994). In view of the critical role played by the globus pallidus in the control of movements (Chesselet and Delfs, 1996; Obeso et al. 2000), we have examined the behavioral effects of endomorphin-1 administered bilaterally into the globus pallidus of conscious rats. This in vivo study was complemented by an in vitro analysis of endomorphin-1 in cells expressing the cloned mouse $\mu$-opioid receptor to further characterize the effect of endomorphin-1 at this receptor.

\section{MATERIALS AND METHODS}

Surgery. All procedures were performed on male Sprague Dawley rats (270-310 gm; Charles River, Wilmington, MA) in accordance with the National Institutes of Health Guide for the Care and Use of Laboratory Animals and were approved by the local animal care committee. Before surgery, rats were maintained on a $12 \mathrm{hr}$ light/dark schedule with food pellets and water ad libitum. Rats were anesthetized with equithesin (prepared as per instruction of Janssen-Salbutry Laboratories, Kansas City, MO) and implanted with cannulas for bilateral microinfusion of drug into the globus pallidus (anteroposterior, $-1.3 \mathrm{~mm}$ from bregma; 

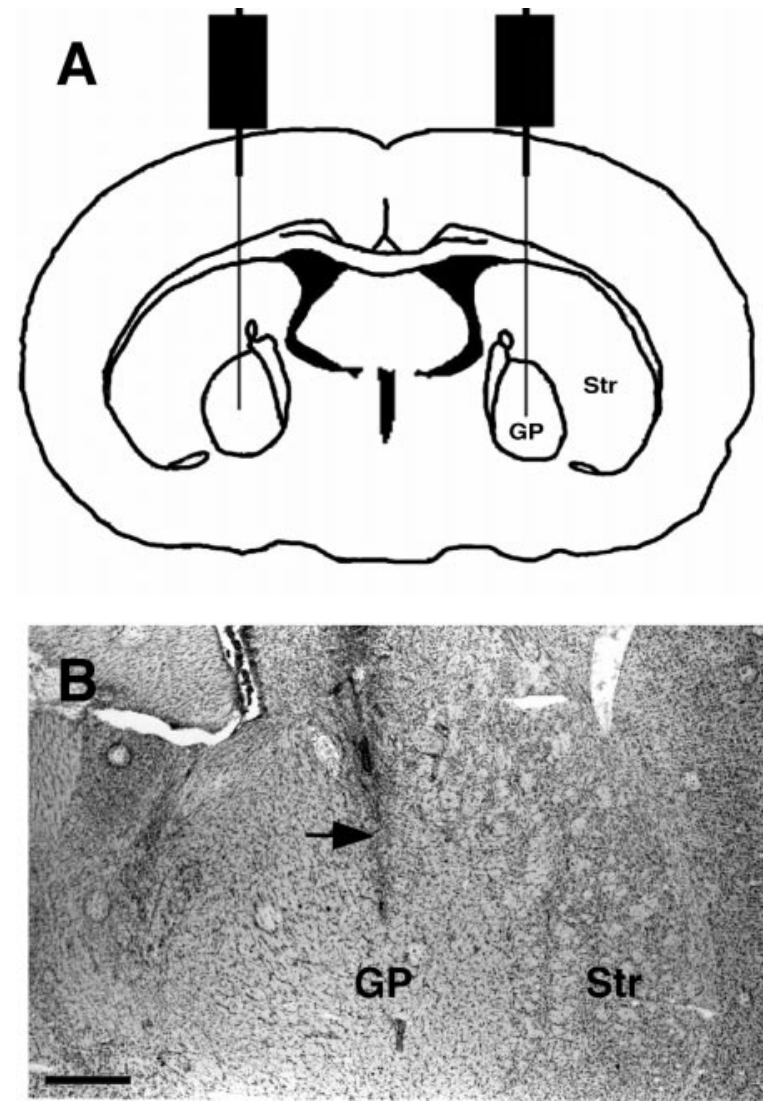

Figure 1. A, Schematic diagram of the experimental model. Drugs were locally administered bilaterally in the globus pallidus of conscious rats via indwelling cannulas. $B$, A representative Nissl-stained section showing the needle tract (arrow) created by the insertion of the internal cannula into the right globus pallidus. Scale bar, $0.2 \mathrm{~mm}$. GP, Globus pallidus; Str, striatum.

mediolateral, $\pm 3.3 \mathrm{~mm}$ relative to interaural zero; and dorsoventral, 5.8 $\mathrm{mm}$ below the surface of the cortex) (Paxinos and Watson, 1986) (Fig. 1). Two guide cannulas were positioned using a copper rectangular plate with two holes centered $6.6 \mathrm{~mm}$ apart; the plate was implanted within the head block during surgery. Details of the surgical procedure and injection equipment have been described previously (Parry et al., 1994; EberleWang et al., 1996). Briefly, the guide shafts were made of 22 ga cannulas cut to a length of $18 \mathrm{~mm}$, and the injector was made of a piece of fused silica (outer diameter, $150 \mu \mathrm{m}$; inner diameter, $75 \mu \mathrm{m}$ ) threaded through a 28 ga internal cannula such that the tip of the fused silica extended 1 $\mathrm{mm}$ from the end of the internal cannula shaft. Behavioral testing began 1 week after surgery.

Behavioral testing. On the day of behavioral testing, each rat was adapted to a quiet room in a clear plastic cylindrical chamber (diameter, 12 inches; height, 18 inches) for $1 \mathrm{hr}$ before any local or systemic drug (or vehicle) administration. Immediately before the onset of behavioral observations, a $\mu$-selective agonist, endomorphin- 1 or [D-Ala ${ }^{2}-N-\mathrm{Me}-$ $\mathrm{Phe}^{4}$-Glycol ${ }^{5}$-enkephalin (DAMGO), or its vehicle (0.9\% saline) was administered locally into the globus pallidus. During drug infusions, the conscious rat was gently handheld, and the drug was infused directly into the globus pallidus via an injector placed within the surgically implanted guide cannula. All inf usions were bilateral, done serially starting with the left globus pallidus. A volume of $0.3 \mu \mathrm{l}$ was infused over $48 \mathrm{sec}$ on each side. The injector was left in place for an additional $60 \mathrm{sec}$ to permit diffusion of the drug away from the injector tip. In experiments that included the use of antagonists, the antagonist was administered either 15 (naloxone) or $5\left[\mathrm{Cys}^{2}-\mathrm{Tyr}^{3}-\mathrm{Orn}^{5}-\mathrm{Pen}^{7}\right.$ amide (CTOP)] min before local drug application.

Two types of behaviors were measured after injection of endomorphin-1 into the globus pallidus: catalepsy and orofacial dyskinesia. Catalepsy was measured using a standard horizontal bar apparatus suspended $11 \mathrm{~cm}$ above the table top. Orofacial dyskinesia was measured after the local administration of drugs into the globus pallidus; then the rats were returned to the testing chamber and observed continuously for $60 \mathrm{~min}$ for bouts of orofacial movements. An oral bout was defined as any combination of continuous, nondirected orofacial movements, including vacuous chewing, gaping, jaw tremor, and tongue protrusion. Those oral movements that were directed toward an object or purpose, such as grooming or ingestion, were not counted. The frequency of oral bouts was quantified over the 60 min observation period. The duration of each bout was not measured. Both behaviors were measured by an observer who was blind to the treatment conditions. In all studies, at least 4 drug-free days intervened between test days. The same animals received both drug and vehicle administrations, and the order of treatment was randomized. In the experiments involving opioid antagonists, the corresponding baselines were measured $3 \mathrm{~d}$ before each study. Significance was defined as $p<0.05$ by a repeated measures ANOVA followed by either a Dunnett's test or Duncan's multiple range test using StatView version 5.0.1 (SAS Institute, Cary, NC).

Drugs used in behavioral testing. Endomorphin-1 [molecular weight (MW), $610.7 \mathrm{gm} / \mathrm{mol}$ ], DAMGO (MW, $513.7 \mathrm{gm} / \mathrm{mol}$ ), naloxone $\mathrm{HCl}$ (MW, $363.8 \mathrm{gm} / \mathrm{mol}$ ), and CTOP (MW, $1062 \mathrm{gm} / \mathrm{mol})$ were dissolved in distilled water and stored in aliquots at $-20^{\circ} \mathrm{C}$. On each experimental day, aliquots were thawed and brought to concentration with $0.9 \%$ saline. Drug doses were calculated on the basis of the free base weight of each compound. The dosage of drugs administered locally in the globus pallidus is expressed as the amount of drug administered in each hemisphere. Endomorphin-1 was generously donated by Dr. Murray Goodman (University of California, San Diego). Naloxone was kindly contributed by Dr. Chris Evans (University of California, Los Angeles). DAMGO and CTOP were purchased from Research Biochemicals (Natick, MA).

Placement verification. At the completion of the behavioral studies for each surgical group, all rats were anesthetized and killed by decapitation. Brains were removed, rapidly frozen on powdered dry ice, and stored at $-80^{\circ} \mathrm{C}$. Sections $20 \mu \mathrm{m}$ thick were cut on a cryostat (CM1800; Leica, Nussloch, Germany) through the globus pallidus. Tissue sections from each brain were fixed for $30 \mathrm{~min}$ in $4 \%$ paraformaldehyde and stained with cresyl violet for verification of cannula placement within the globus pallidus. Only data from rats in which cannula placement was accurately verified bilaterally within the globus pallidus were included in the statistical analysis. Successful bilateral placement was seen in $>80 \%$ of all surgeries performed. A representative tissue section depicting cannula placement in the globus pallidus is shown in Figure $1 B$.

Cell culture. Human embryonic kidney (HEK) 293 cells were grown and maintained in MEM with Earle's salts (Life Technologies, Grand Island, NY) containing $10 \%$ fetal calf serum, $1000 \mathrm{U} / \mathrm{ml}$ penicillin, and streptomycin sulfate in $10 \% \mathrm{CO}_{2}$ at $37^{\circ} \mathrm{C}$. The mouse $\mu$-opioid receptor cDNA, human $\kappa$ receptor cDNA, and the mouse $\delta$ receptor cDNA, in the expression vector pcDNA3 (Invitrogen, San Diego, CA), were transfected stably into HEK 293 cells by a modification of the calcium phosphate protocol (Blake et al., 1997). Stable transformants were selected in growth media containing $1 \mathrm{mg} / \mathrm{ml}$ Geneticin (Life Technologies, Rockville, MD) and maintained in $\mathrm{T} 75 \mathrm{~cm}^{2}$ tissue culture flasks in $10 \% \mathrm{CO}_{2}$ at $37^{\circ} \mathrm{C}$.

Radioligand binding studies. Receptor binding studies were performed using membranes from stably transfected HEK 293 cells expressing the $\mu-, \kappa^{-}$, or $\delta$-opioid receptor. Membranes were prepared, and receptor binding studies were conducted as described (Raynor et al., 1994; Blake et al., 1997). Briefly, stably transfected HEK 293 cell monolayers were harvested in $6 \mathrm{ml}$ of $50 \mathrm{~mm}$ Tris- $\mathrm{HCl}, \mathrm{pH} 7.8$, with $1 \mathrm{~mm}$ EGTA, $5 \mathrm{~mm}$ $\mathrm{MgCl}_{2}, 10 \mu \mathrm{g} / \mathrm{ml}$ pepstatin, $10 \mu \mathrm{g} / \mathrm{ml}$ leupeptin, $200 \mu \mathrm{g} / \mathrm{ml}$ bacitracin, and $0.5 \mu \mathrm{g} / \mathrm{ml}$ aprotinin and centrifuged at $24,000 \times g$ for $10 \mathrm{~min}$ at $4^{\circ} \mathrm{C}$. The cell pellet was homogenized at setting 2.5 for $50 \mathrm{sec}$ with a Brinkman Polytron, and the resulting homogenate was centrif uged at $48,000 \times g$ for $15 \mathrm{~min}$ at $4^{\circ} \mathrm{C}$. The pellet was then resuspended by homogenization and used in the radioligand binding assays. For agonist pretreatment studies, a 10 -fold concentration stock of agonist was diluted into growth medium and added to individual culture flasks. The final concentration of all agonists used in regulation studies was $1 \mu \mathrm{M}$. Cell monolayers were harvested $3 \mathrm{hr}$ after the initiation of the treatment.

cAMP accumulation studies. Stably transfected HEK 293 cells expressing the $\mu$ receptor were subcultured in 12-well culture plates and allowed to recover for $72 \mathrm{hr}$ before experiments. For the cAMP experiments, the medium was removed and replaced with $1 \mathrm{ml}$ of growth medium containing $0.5 \mathrm{~mm}$ isobutylmethylxanthine, and the cells were incubated for $30 \mathrm{~min}$ at $37^{\circ} \mathrm{C}$. The culture medium was then removed, the cells washed, 


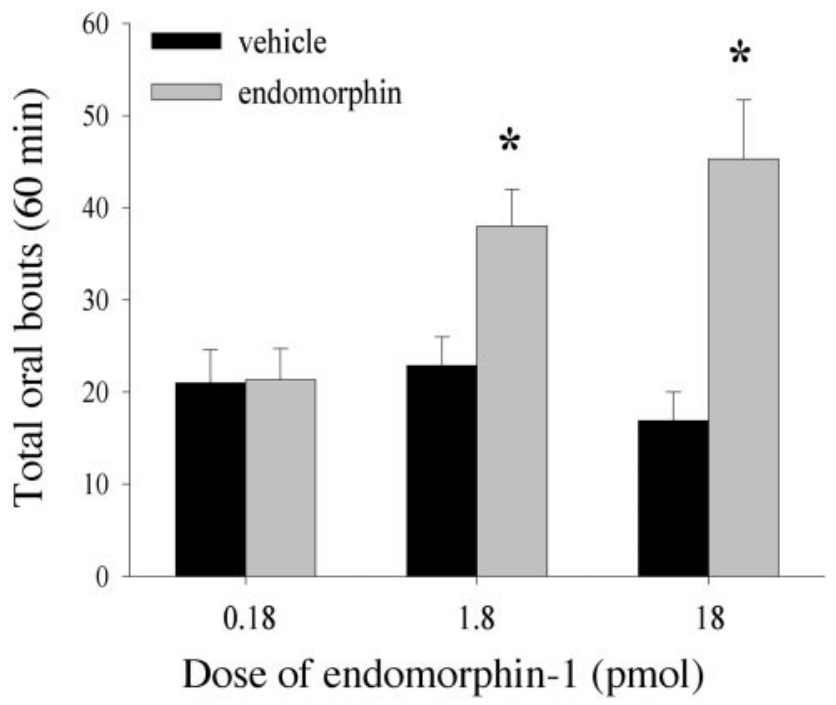

Figure 2. Local administration of endomorphin-1 (0.18, 1.8, and 18 pmol) in the globus pallidus dose-dependently induced orofacial dyskinesia in rats $(n=7-8)$. Data are expressed as total oral bouts per $60 \mathrm{~min}$ period. $* p<0.05$, compared with corresponding vehicle response in the same rats, according to Student's paired $t$ test.

and fresh medium, with or without $10 \mu \mathrm{M}$ forskolin and opiates, was added. After a $5 \mathrm{~min}$ incubation at $37^{\circ} \mathrm{C}, 1.0 \mathrm{ml}$ of $0.1 \mathrm{~N} \mathrm{HCl}$ was added, and the monolayers were frozen overnight at $-20^{\circ} \mathrm{C}$. For the determination of the cAMP content of each well, the monolayers were thawed, placed on ice, and sonicated, and the intracellular cAMP levels were measured by radioimmunoassay (Amersham, Buckinghamshire, UK). Data obtained from dose-response curves were analyzed by nonlinear regression analysis with Graph Pad Prism version 2.01 (Graph Pad, San Diego, CA).

\section{RESULTS}

\section{Bilateral administration of endomorphin-1 in the globus pallidus does not induce catalepsy}

Because local administration of a GABA agonist (Matsui and Kamioka, 1978) or dopamine antagonists (Hauber and Lutz, 1999 ) in the globus pallidus has been shown to induce catalepsy in rats, we tested for this behavior after the administration of endomorphin-1. Bilateral infusion of endomorphin-1 (18 pmol per side) into the globus pallidus did not induce catalepsy when tested 15, 30, 60, 90, and 120 min postinfusion $(n=4$; data not shown). At a lower dose (1.8 pmol per side), in another group of animals $(n=7)$, endomorphin-1 did not induce catalepsy when tested $60 \mathrm{~min}$ after infusion.

\section{Bilateral administration of endomorphin-1 in the globus pallidus induces a sustained increase in orofacial dyskinesia}

Bilateral infusion of endomorphin-1 into the globus pallidus induced a dose-dependent increase in the total number of nondirected orofacial movements observed in the 60 min test period, when compared with the effect of vehicle in the same animals (Fig. 2). A dose of 0.18 pmol per side failed to induce an increase in orofacial dyskinesia over the total observation period $(60 \mathrm{~min})$ and when examined in individual 10 min periods (Fig. 3A) (twoway repeated measures ANOVA; dose, $F_{(1,12)}=0.003$, NS; time, $\left.F_{(5,60)}=0.24, p<0.05\right)$. A dose of 1.8 pmol endomorphin-1 induced a significant increase in orofacial dyskinesia over the 60 min observation period (Fig. 2). Analysis of the time course of the behavior confirmed the effect of the dose (Fig. 3B) (two-way repeated measures ANOVA; $\left.F_{(1,12)}=8.63 ; p<0.05\right)$ without an effect of time (two-way repeated measures ANOVA; $F_{(5,60)}=$ 0.45 , NS). A dose of 18 pmol endomorphin-1 also elicited an increase in orofacial dyskinesia when measured over the $60 \mathrm{~min}$ observation (Fig. 2). Analysis of the time course confirmed the effect of the dose (Fig. 3C) (two-way repeated measures ANOVA; $F_{(1,14)}=16.25 ; p<0.005$ ) with an effect of time (two-way repeated measures ANOVA; $F_{(5,70)}=2.50 ; p<0.05$ ). The effect induced by 18.0 pmol endomorphin- 1 was significantly different from controls from 20-60 min after drug administration (Fig. 3C) (Dunnett's test, $p<0.05$ ).

In two cases in which the cannula placement was outside the globus pallidus on both sides, one in the striatum anterior to the globus pallidus and the other in the internal capsule posterior to the globus pallidus, administration of endomorphin-1 (18 pmol per side) failed to elicit nondirected orofacial movements above baseline levels. The rat with cannula placement in the striatum showed 26 oral bouts after administration of vehicle and 22 oral bouts after 18 pmol endomorphin- 1 during the 60 min observation. Similarly, the rat with placement in the internal capsule showed 17 oral bouts after vehicle and 16 oral bouts after 18 pmol endomorphin-1.

\section{Bilateral administration of the full $\mu$-opioid receptor agonist DAMGO in the globus pallidus produces a transient increase in oral dyskinesia}

To confirm that stimulation of $\mu$-opioid receptors in the globus pallidus by a classical $\mu$ agonist reproduces the behavioral effect induced by endomorphin-1, DAMGO (18 pmol), a synthetic peptide that is a selective full agonist at the $\mu$-opioid receptor (Yu et al., 1997), or its vehicle ( $0.9 \%$ saline), was bilaterally administered in the globus pallidus. Unlike endomorphin-1 at the same dose (18 pmol), DAMGO did not increase the total number of oral bouts observed over the 60 min observation period (data not shown), nor did it induce a sustained increase in orofacial dyskinesia (Fig. 3D) (two-way repeated measures ANOVA; dose, $F_{(1,12)}=0.56$, NS; time, $F_{(5,60)}=0.72$, NS). However, this dose of DAMGO did produce a significant increase in orofacial dyskinesia in the first 10 min postinf usion (Fig. 3D) (Dunnett's test; $p<$ $0.05)$, after which the response returned to the baseline level.

\section{Administration of the opioid antagonists naloxone and CTOP blocks orofacial dyskinesia induced by endomorphin-1}

To directly confirm a role of the $\mu$-opioid receptors in the effect of local administration of endomorphin-1 in the globus pallidus, we administered drugs having antagonistic properties at this receptor before the infusion of endomorphin-1 into the globus pallidus. A 15 min pretreatment with the opioid antagonist naloxone $(0.2 \mathrm{mg} / \mathrm{kg}$, s.c.) blocked orofacial dyskinesia induced by endomorphin-1 (18 pmol) (Fig. 4A) (one-way repeated measures ANOVA; $\left.F_{(2,10)}=6.9 ; p=0.01\right)$. Further supporting the selective involvement of $\mu$-opioid receptors in the endomorphin-induced behavioral effect, the bilateral administration of CTOP $(1.8 \mathrm{pmol})$, a selective $\mu$-opioid receptor peptide antagonist, $5 \mathrm{~min}$ before the administration of endomorphin-1 (18 pmol) also blocked orofacial dyskinesia (Fig. $4 B$ ) (one-way repeated measures ANOVA; $F_{(2,14)}$ $=21.0 ; p<0.0001)$. In these two experiments that were conducted in separate groups of animals, endomorphin-1 (18 pmol) produced consistent orofacial dyskinetic responses when not administered with the antagonists (Fig. 4). 
A

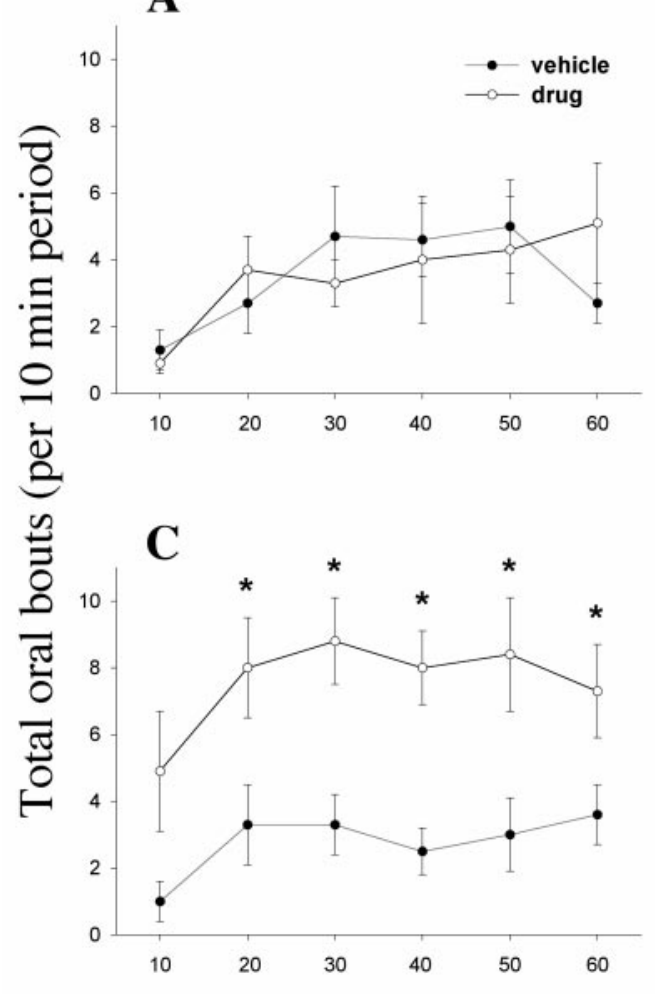

B

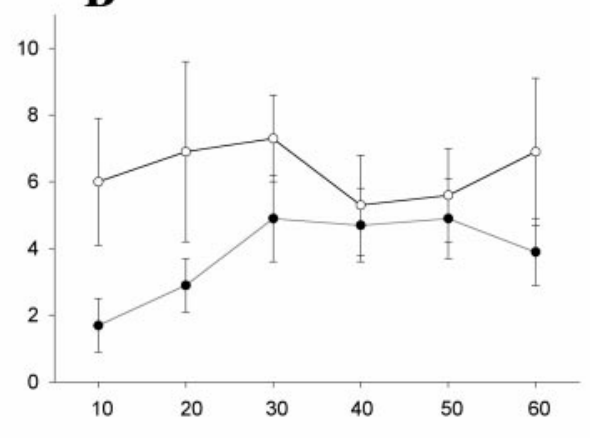

D

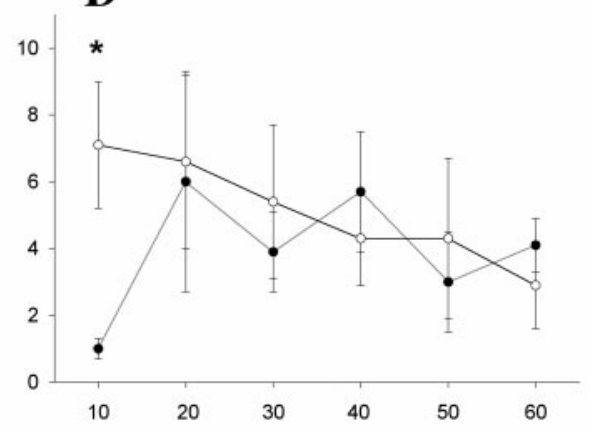

\section{Minutes post-infusion}

Figure 3. Time course of orofacial dyskinesia induced immediately after local administration of 0.18 pmol endomorphin-1 $(A), 1.8$ pmol endomorphin-1 $(B), 18.0$ pmol endomorphin-1 $(C)$, or 18.0 pmol DAMGO $(D)$ in the globus pallidus $(n=7-8)$. Data are expressed as total oral bouts per 10 min period. ${ }^{*} p<0.05$, compared with corresponding vehicle response in the same rats at the same time point, according to Dunnett's test after a two-way repeated measures ANOVA.

\section{Endomorphin-1 selectively binds to the cloned $\mu$ - opioid receptor and inhibits stimulated CAMP accumulation without desensitization}

To further investigate the selectivity of endomorphin-1, we tested it for binding to cloned opioid receptors expressed in HEK 293 cells and its ability to inhibit forskolin stimulated cAMP accumulation. Endomorphin-1 did not bind to the cloned $\kappa$ receptor or the cloned $\delta$ receptor $\left(K_{\mathrm{i}}>2000 \mathrm{nM}\right)$. In contrast, the $K_{\mathrm{i}}$ value for endomorphin-1 displacement of ${ }^{3} \mathrm{H}$-naloxone binding to the cloned $\mu$ receptor was $18.2 \pm 2.1 \mathrm{~nm}$ (the density of receptor as assessed by saturation analysis of ${ }^{3} \mathrm{H}$-naloxone binding was 8.6 $\mathrm{pmol} / \mathrm{mg}$ protein with a $K_{\mathrm{d}}$ of $1.3 \mathrm{~nm}$ ). The affinity of endomorphin-1 was slightly less than the affinity of the selective $\mu$ agonist DAMGO (3.3 $\pm 0.32 \mathrm{~nm})$ and methionine enkephalin $(1.4 \pm 0.5 \mathrm{nM})$ for the $\mu$-opioid receptor (Fig. $5 A)$. Our results confirm that endomorphin-1 selectively binds to the $\mu$-opioid receptor.

Further confirming an agonist effect on $\mu$ receptors, endomorphin-1 inhibited forskolin-stimulated cAMP accumulation in HEK 293 cells expressing the cloned $\mu$-opioid receptor (Fig. 5B). The maximum effectiveness for endomorphin-1 to inhibit cAMP accumulation was less than that induced by the full $\mu$ agonist DAMGO (Fig. 5B). This is in agreement with evidence that endomorphin-1 is a partial agonist at the rat $\mu$-opioid receptor (Hosohata et al., 1998; Sim et al., 1998) (but see Gong et al., 1998). No apparent desensitization of the $\mu$ receptor was observed after $3 \mathrm{hr}$ of treatment of the $\mu$ receptor with $1 \mu \mathrm{M}$ endomorphin-1 (Table 2). Similar results were observed after pretreatment with met-enkephalin or DAMGO (Table 2).

\section{DISCUSSION}

The present results demonstrate a novel behavioral effect of the endogenous opioid peptide endomorphin-1, distinct from its previously described analgesic effect. Both in vivo and in vitro data indicate a lack of desensitization of opioid receptors by endomorphin, suggesting that this endogenous peptide may be involved in sustained motor behaviors.

\section{The opioid system and dyskinesia}

The endomorphins are the only endogenous opiates known to bind selectively and with high affinity to the $\mu$-opioid receptor. In agreement with a role for $\mu$-opioid receptors in endomorphininduced orofacial dyskinesia, this behavior was blocked by peripheral administration of naloxone at a dose $(0.2 \mathrm{mg} / \mathrm{kg}$, s.c. $)$ that has been shown to effectively block the $\mu$-opioid receptor but not the $\delta$ receptor (Mokha, 1988). However, because naloxone has similar binding affinities for $\mu$ - and $\kappa$-opioid receptors (Raynor et al., 1994) and all three opioid receptor types are expressed in the globus pallidus (Mansour et al., 1995), an interaction of endomorphin-1 with the $\kappa$-opioid receptor could not be ruled out with naloxone alone. Therefore, endomorphin-1 was also administered after a local pretreatment of CTOP, a selective $\mu$ antagonist that does not bind to $\kappa$ - or $\delta$-opioid receptors (Raynor et al., 1994). This antagonist completely blocked the 


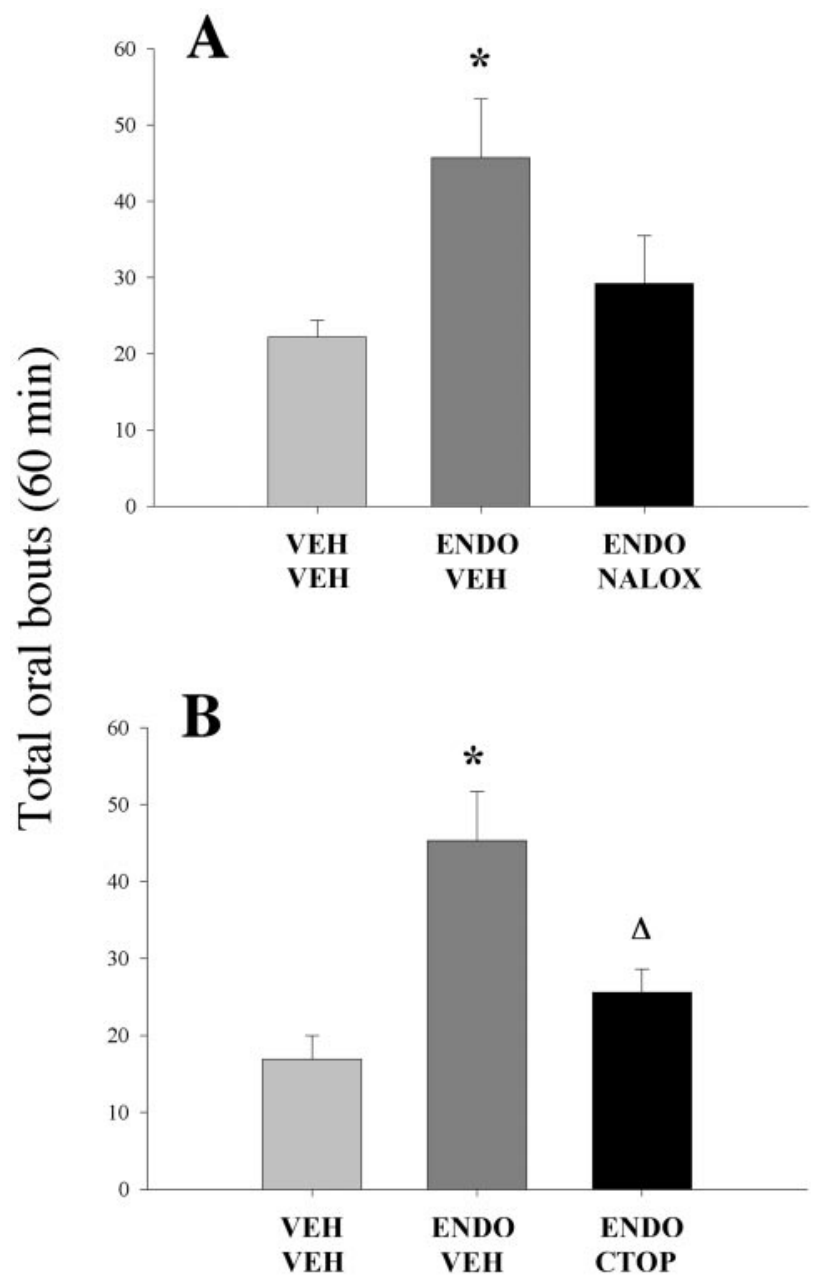

Figure 4. A, Systemic pretreatment (15 min) with the nonselective opioid antagonist naloxone $(0.2 \mathrm{mg} / \mathrm{kg}$, s.c.) blocked orofacial dyskinesia induced by administration of endomorphin- 1 in the globus pallidus $(18 \mathrm{pmol} ; n=$ $6)$. $B$, Local pretreatment $(5 \mathrm{~min})$ with the selective $\mu$-opioid receptor antagonist CTOP (1.8 pmol) blocked orofacial dyskinesia induced by endomorphin-1 (18 pmol; $n=8)$. Data are expressed as mean \pm SEM of total oral bouts during the $60 \mathrm{~min}$ period immediately after endomorphin administration. ${ }^{*} p<0.05$ compared with baseline data, according to ANOVA followed by Dunnett's test. $\Delta p<0.05$ compared with endomorphin-1/vehicle (s.c.) data according to ANOVA, followed by Duncan's multiple range test. $N A L O X$, Naloxone; ENDO, endomorphin-1; VEH, vehicle.

behavioral effect induced by endomorphin-1. Together, these data confirm the involvement of $\mu$-opioid receptors in endomorphin-induced dyskinesia. The lack of a similar effect after drug injections outside the globus pallidus and the expected restricted diffusion of a naturally occurring peptide in vivo strongly suggest that this effect is mediated by $\mu$-opioid receptors in the globus pallidus.

Previous studies of local administration of the synthetic $\mu$ agonists FK 33-824 (Dewar et al., 1985) and morphine (Anagnostakis et al., 1992) into the globus pallidus have revealed a robust increase in locomotor activity. An induction of orofacial dyskinesia may have been missed in these previous studies because locomotor activity was recorded automatically, without detailed examination of the behavior of the animal. Although locomotor activity was not systematically analyzed in our studies, endomorphin-1 and DAMGO did not induce robust increases in
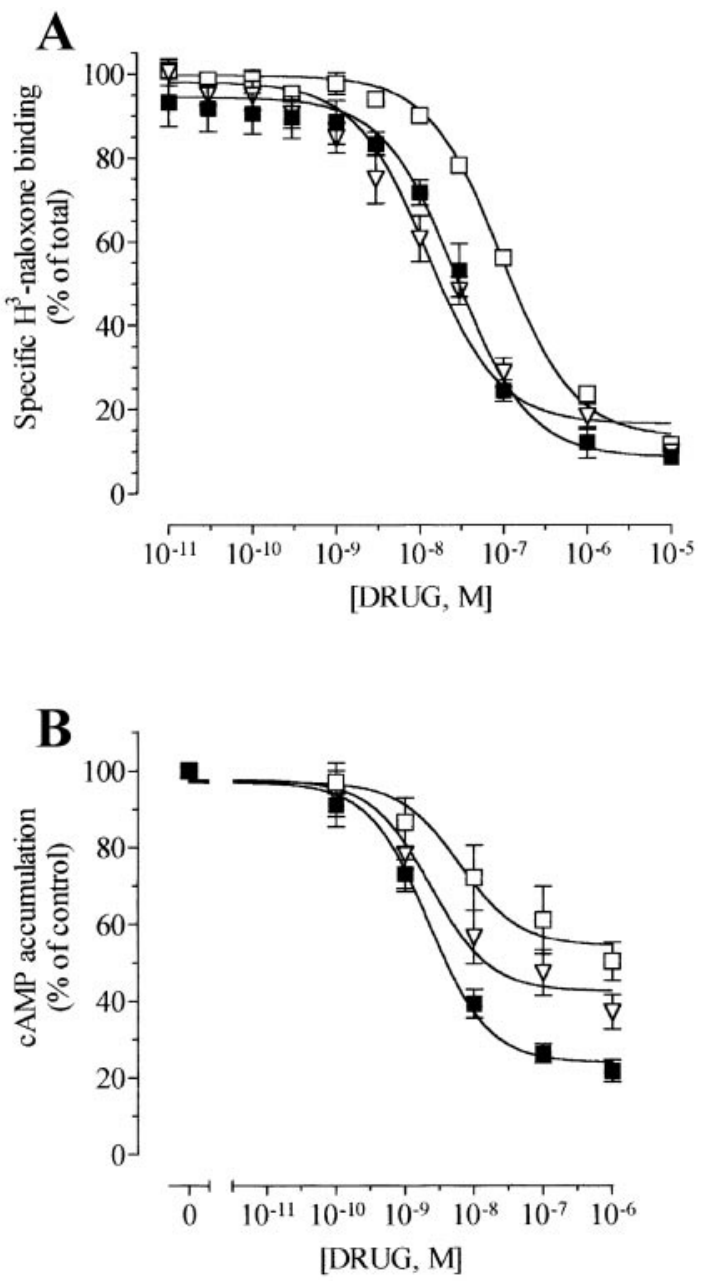

Figure 5. A, Displacement of $\left[{ }^{3} \mathrm{H}\right]$-naloxone binding with DAMGO ( $\square$ ), met-enkephalin $(\nabla)$, and endomorphin $(\square)$. For each drug, the data represent the mean \pm SEM for three separate inhibition curves, each assayed in duplicate. The results are presented as percentage of maximal specifically bound radioligand $\left[{ }^{3} \mathrm{H}\right]$-naloxone. $B$, Concentrationdependent inhibition of intracellular cAMP accumulation in $\mu$-FLAG expressing HEK 293 cells by DAMGO $(\boldsymbol{\square})$, met-enkephalin $(\nabla)$, and endomorphin $(\square)$. The inhibition of forskolin-stimulated cAMP accumulation is expressed as a percentage of the forskolin control. Intracellular cAMP levels of the cells incubated with forskolin alone served as controls $(100 \%)$. Forskolin-stimulated cAMP levels were typically 5- to 20 -fold higher than basal values. Basal levels were subtracted from the forskolin levels obtained. The dose-response curves were determined by computer analysis using Graph Pad Prism version 2. The data presented are the means \pm SEM of three or more separate experiments, each performed in duplicate.

locomotion in our experiments. This discrepancy may be related to differences in receptor selectivity. Endomorphin-1 (see Results) and DAMGO (Raynor et al., 1994) showed exclusive selectivity for the cloned $\mu$-opioid receptor. In contrast, Dewar et al. (1985) showed that FK 33-824, even at low doses, mediated effects characteristic of $\kappa$-opioid receptors. Similarly, the pharmacological profile of morphine shows some affinity for the cloned $\kappa$ receptor (Raynor et al., 1994), which may be significant at high doses. Indeed, the lowest dose of morphine used by Anagnostakis et al. (1992) was $10^{3}$ times greater than the highest dose of endomorphin- 1 in our studies. A role for $\partial$ and $\kappa$ receptors in stimulating coordinated locomotor activity is further supported by the ability of selective antagonists for these receptors to block 


\begin{tabular}{|c|c|c|}
\hline Ligand & $\mathrm{EC}_{50}(\mathrm{nM})$ & Maximum inhibition (\%) \\
\hline Endomorphin-1 & $6.3 \pm 2.0$ & $51.0 \pm 4.7$ \\
\hline Met-enkephalin & $1.7 \pm 0.4$ & $63.0 \pm 4.6$ \\
\hline Morphine & $7.1 \pm 1.6$ & $73.0 \pm 2.1$ \\
\hline DAMGO & $2.1 \pm 0.6$ & $78.3 \pm 2.9$ \\
\hline
\end{tabular}

apomorphine-induced rotations in rats with unilateral nigrostriatal lesions (Henry and Brotchie, 1996), whereas cyprodime, a selective $\mu$-opioid receptor antagonist, had no effect on the behavior (Henry and Brotchie, 1996).

\section{Endogenous endomorphins in the globus pallidus}

Although the globus pallidus contains neurons that express very high levels of $\mu$-opioid receptor mRNA, neither endomorphin-1 nor endomorphin-2 immunoreactivities have been detected in this brain region with classical immunohistochemical techniques (Martin-Schild et al., 1999). However, immunoreactivity for endomorphin-2 has been found in the rat globus pallidus in a more recent study (Pierce and Wessendorf, 2000) with a more sensitive method of detection than that used previously (MartinSchild et al., 1999). Specifically, a light to moderate density of endomorphin-2-immunoreactive fibers was observed in the caudal globus pallidus, whereas the rostral half showed a sparse innervation (Pierce and Wessendorf, 2000). Interestingly, this rostrocaudal gradient of endomorphin-2-immunoreactivity corresponds to the distribution of $\mu$ receptor mRNA in the globus pallidus (Delfs et al., 1994). It is therefore possible that moderate levels of endomorphin-1 are present in the globus pallidus and that more sensitive antibodies or detection methods will be necessary to detect the peptide. Failure of immunohistochemical methods to detect functionally significant pathways is not unusual. Alternatively, because endomorphin-1 and endomorphin-2 are pharmacologically similar (Zadina et al., 1997), the effects we have observed after local administration of endomorphin-1 could be mediated by endogenous endomorphin-2. Better tools to determine the precise neuronal location of endomorphin-1 in tissue sections will be necessary to determine the relative contribution of these two endogenous peptides in the globus pallidus.

\section{Endomorphin-1 as a partial agonist at the $\mu$-opioid receptor}

The binding of endomorphin- 1 to the cloned $\mu$-opioid receptor further confirms the high affinity and selectivity of endomorphin-1 for the $\mu$-opioid receptor. The function of endomorphin-1 as a $\mu$-selective agonist was confirmed by its ability to inhibit forskolin-stimulated cAMP accumulation in HEK 293 cells expressing the cloned mouse $\mu$ receptor. Endomorphin-1 inhibited cAMP accumulation less than the full agonist DAMGO, suggesting that endomorphin-1 is a partial agonist. This finding is consistent with recent reports which showed that endomorphin-1 was a partial agonist at the $\mu$-opioid receptors in rat brain (Sim et al., 1998) and in cells expressing the cloned (Hosohata et al., 1998) and native (Harrison et al., 1998) human $\mu$ receptor as compared with DAMGO. Furthermore, the absence of desensitization of the cAMP response indicates that endomorphin-1 does not rapidly desensitize the $\mu$-opioid receptor and is consistent with both the stable and sustained orofacial dyskinetic response and the prolonged analgesic effects of the endomorphins (Zadina et al., 1997).

In contrast to endomorphin-1, the synthetic selective $\mu$-opioid receptor agonist, DAMGO, at the same dose (18 pmol), produced a transient increase in orofacial dyskinesia that rapidly returned to baseline levels. Although the duration of the behavioral effect induced by DAMGO could be dose-dependent, the rapid desensitization observed is unlikely to be attributable to the use of a submaximal dose of DAMGO because our results from transfected cells show that DAMGO is a more potent agonist at the cloned $\mu$-opioid receptor than endomorphin-1. However, $3 \mathrm{hr}$ of continuous exposure of the cloned $\mu$ receptor to DAMGO did not result in desensitization of adenylate cyclase as determined by inhibition of forskolin-stimulated cAMP formation. These in vitro data suggest that the rapid desensitization of DAMGO-mediated behavioral responses could be attributable to the involvement of an adaptive regulatory system that does not regulate $\mu$-opioid receptor-adenylate cyclase coupling but does regulate $\mu$-opioid receptor coupling to other effector systems. This is consistent with previous molecular (Yu et al., 1997) and electrophysiological (Mayer et al., 1995; Tallent et al., 1998) studies that have reported a selective diminution in some, but not other, functional responses to DAMGO after previous exposure to the drug. For example, the cloned rat $\mu$-opioid receptor expressed in a pituitary cell line has been shown to uncouple from potassium channels but not adenylate cyclase after exposure to DAMGO (Tallent et al., 1998).

\section{Functional implications}

Dyskinesia are debilitating uncoordinated hyperkinetic movements that remain a major complication of L-DOPA treatment for Parkinson's disease (Chase et al., 1994) and chronic neuroleptic use (Tarsy and Baldessarini, 1984). A growing body of evidence implicates a role for the opioid system in the development of dyskinesia. In clinical studies, opioid antagonists such as naloxone and naltrexone have been shown to significantly reduce dyskinesia in patients with tardive dyskinesia (Lindenmayer et al., 1988), levodopa-induced dyskinesia (Trabucchi et al., 1982; Sandyk and Snider, 1986), and Tourette's syndrome (Kurlan et al., 1991). Consistent with the clinical data, neuroleptic-induced orofacial dyskinesia in rats have been blocked with peripherally administered naloxone (Pollack et al., 1991; Stoessl et al., 1993). The therapeutic efficacy of naloxone may be caused by the blockade of

Table 2. Agonist $(1 \mu \mathrm{M})$ pretreatment $(3 \mathrm{hr})$ effects on opioid inhibition of forskolin stimulated cAMP levels for the cloned $\mu$-opioid receptor

\begin{tabular}{|c|c|c|c|c|}
\hline \multirow[b]{2}{*}{ Ligand } & \multicolumn{2}{|c|}{ Untreated cells } & \multicolumn{2}{|c|}{ Agonist pretreated cells } \\
\hline & $\mathrm{EC}_{50}(\mathrm{nM})$ & Maximum inhibition (\%) & $\mathrm{EC}_{50}(\mathrm{nM})$ & Maximum inhibition (\%) \\
\hline Endomorphin-1 & $6.3 \pm 2.0$ & $51.2 \pm 4.7$ & $23.0 \pm 8.0$ & $40.3 \pm 5.5$ \\
\hline Met-enkephalin & $1.7 \pm 0.3$ & $63.0 \pm 4.6$ & $2.6 \pm 0.5$ & $66.2 \pm 4.8$ \\
\hline DAMGO & $2.1 \pm 0.6$ & $78.3 \pm 2.9$ & $1.8 \pm 0.4$ & $83.0 \pm 2.5$ \\
\hline
\end{tabular}


an increased transmission of endogenous opiates during dyskinesia.

Similar to the effects of endomorphin-1, previous studies have shown that the local administration of the GABA receptor antagonist bicuculline in the globus pallidus stimulates dyskinesia (Crossman et al., 1988; Matsumura et al., 1995). In contrast, both local administration of the GABA agonist muscimol in the globus pallidus and chronic peripheral treatment with the opioid antagonist naloxone induced catalepsy in rats (Matsui and Kamioka, 1978; Egan et al., 1995). Thus, endomorphin and GABA induce opposite behavioral effects in the globus pallidus. Accordingly, alterations in the balance of these endogenous neurotransmitters in the globus pallidus could play a key role in the control of movement and the development of dyskinesia.

\section{REFERENCES}

Albin RL, Young AB, Penney JB (1989) The functional anatomy of basal ganglia disorders. Trends Neurosci 12:366-375.

Albin RL, Qin Y, Young AB, Penney JB, Chesselet M-F (1991) Preproenkephalin messenger RNA-containing neurons in striatum of patients with symptomatic and presymptomatic Huntington's disease: an in situ hybridization study. Ann Neurol 30:542-549.

Anagnostakis Y, Kribos Y, Spyraki C (1992) Pallidal substrate of morphine-induced locomotion. Eur Neuropsycopharmacol 2:65-72.

Blake AD, Bot G, Freeman JC, Reisine T (1997) Differential opioid agonist regulation of the mouse mu opioid receptor. J Biol Chem 272:782-790.

Chase TN, Engber TM, Mouradian MM (1994) Palliative and prophylactic benefits of continuously administered dopaminomimetics in Parkinson's disease. Neurology 44:S15-S18.

Chesselet MF, Delfs JM (1996) Basal ganglia and movement disorders: an update. Trends Neurosci 19:417-422.

Crossman AR, Mitchell IJ, Sambrook MA, Jackson A (1988) Chorea and myoclonus in the monkey induced by gamma-aminobutyric acid antagonism in the lentiform complex. Brain 111:1211-1233.

Delfs JM, Kong H, Mestek A, Chen Y, Yu L, Reisine T, Chesselet M-F (1994) Expression of mu opioid receptor mRNA in rat brain: an in situ hybridization study at the single cell level. J Comp Neurol 345:46-68.

Dewar D, Jenner P, Marsden CD (1985) Behavioral effects in rats of uniltateral and bilateral injections of opiate agonists into the globus pallidus. Neuroscience 15:41-46.

Eberle-Wang K, Lucki I, Chesselet MF (1996) A role for the subthalamic nucleus in 5-HT2C-induced oral dyskinesia. Neuroscience 72 : 117-128.

Egan MF, Ferguson JN, Hyde TM (1995) Effects of chronic naloxone administration on vacuous chewing movements and catalepsy in rats treated with long-term haloperidol decanoate. Brain Res Bull 38:355363.

Gerfen CR, McGinty JF, Young WSD (1991) Dopamine differentially regulates dynorphin, substance $\mathrm{P}$, and enkephalin expression in striatal neurons: in situ hybridization histochemical analysis. J Neurosci 11:1016-1031

Gong J, Strong JA, Zhang S, Yue X, DeHaven RN, Daubert JD, Cassel JA, Yu G, Mansson E, Yu L (1998) Endomorphins fully activate a cloned human mu opioid receptor. FEBS Lett 439:152-156.

Harrison LM, Kastin AJ, Zadina JE (1998) Differential effects of endomorphin-1, endomorphin-2, and Tyr-W-MIF-1 on activation of G-proteins in SH-SY5Y human neuroblastoma membranes. Peptides 19:749-753.

Hauber W, Lutz S (1999) Dopamine D1 and D2 receptor blockade in the globus pallidus produces akinesia in the rat. Behav Brain Res 106:143-150.

Henry B, Brotchie JM (1996) Potential of opioid antagonists in the treatment of levodopa-induced dyskinesias in Parkinson's disease. Drugs Aging 9:149-158.

Hosohata K, Burkey TH, Alfaro-Lopez J, Varga E, Hruby VJ, Roeske RR, Yamamura HI (1998) Endomorphin-1 and endomorphin-2 are partial agonists at the human $\mu$-opioid receptor. Eur J Pharmacol 346:111-114.

Kurlan R, Majumdar L, Deeley C, Mudholkar GS, Plumb S, Como PG
(1991) A controlled trial of propoxyphene and naltrexone in patients with Tourette's syndrome. Ann Neurol 30:19-23.

Lindenmayer J-P, Gardner E, Goldberg E, Opler LA, Kay SR, van Praag HM, Weiner M, Zukin S (1988) High-dose naloxone in tardive dyskinesia. Psychiatry Res 26:19-28.

Mansour A, Fox CA, Akil H, Watson SJ (1995) Opioid-receptor mRNA expression in the rat CNS: anatomical and functional implications. Trends Neurosci 18:22-29.

Martin-Schild S, Gerall AA, Kastin AJ, Zadina JE (1999) Differential distribution of endomorphin-1 and endomorphin-2-like immunoreactivities in the CNS of the rodent. J Comp Neurol 405:450-471.

Massotte D, Kieffer B (1998) A molecular basis of opiate action. Essays Biochem 33:65-77.

Matsui Y, Kamioka T (1978) Cataleptic and anticataleptic effects of muscimol and gabaculine injected into globus pallidus and substantia nigra, and interactions with haloperidol or benzodiazepines. Naunyn Schmiedebergs Arch Pharmacol 305:219-225.

Matsumura M, Tremblay L, Richard H, Filion M (1995) Activity of pallidal neurons in the monkey during dyskinesia induced by bicuculline in the external pallidum. Neuroscience 65:59-70.

Mayer JH, Steffensen SC, Stevensen SC, Henriksen SJ (1995) Siteselective acute desensitization following local administration of opioid in the hippocampus. Brain Res 686:134-142.

Mokha SS (1988) Effects of selective agonists for the mu and delta opioid receptors on responses of neurons in the superficial and deeper laminae of the trigeminal nucleus caudalis. J Physiol (Lond) 398:85.

Obeso JA, Rodriguez-Oroz MC, Rodriguez M, DeLong MR, Olanow CW (2000) Pathophysiology of levodopa-induced dyskinesias in Parkinson's disease: problems with the current model. Ann Neurol 47:S22-S34.

Parry TJ, Eberle-Wang K, Lucki I, Chesselet M-F (1994) Dopaminergic stimulation of subthalamic nucleus elicits oral dyskinesia in rats. Exp Neurol 128:181-190.

Paxinos G, Watson C (1986) The rat brain in stereotaxic coordinates. Orlando, FL: Academic.

Peckys D, Landwehrmeyer GB (1999) Expression of $\mu, \kappa$, and $\partial$ opioid receptor messenger RNA in the human CNS: a 35P in situ hybridization study. Neuroscience 88:1093-1135.

Pierce TL, Wessendorf MW (2000) Immunocytochemical mapping of endomorphin-2-immunoreactivity in rat brain. J Chem Neuroanat 18:181-207.

Pollack J, Kornetsky C (1991) Naloxone prevents and blocks the emergence of neuroleptic-mediated oral stereotypic behaviors. Neuropsychopharmacology 4:245-249.

Raynor K, Kong H, Chen Y, Yasuda K, Yu L, Bell GI, Reisine T (1994) Pharmacological characterization of the cloned kappa-, delta-, and mu-opioid receptors. Mol Pharmacol 45:330-334.

Sabol SL, Yoshikawa K, Hong J-S (1983) Regulation of methionineenkephalin precursor mRNA in rat striatum by haloparidol and lithium. Biochem Biophys Res Commun 113:391-399.

Sandyk R (1985) The endogenous opioid system in neurological disorders of the basal ganglia. Life Sci 37:1655-1663.

Sandyk R, Snider SN (1986) Naloxone treatment of 1-dopa-induced dyskinesias in Parkinson's disease. Am J Psychiatry 143:118.

Sim LJ, Qixu L, Childers SR, Selley DE (1998) Endomorphinstimulated [35S]GTPgammaS binding in rat brain: evidence for partial agonist activity at $\mu$-opioid receptors. J Neurochem 70:1567-1576.

Stoessl JA, Polanski E, Frydryszak H (1993) The opiate antagonist naloxone suppresses a rodent model of tardive dyskinesia. Mov Disord $8: 445-452$.

Tallent M, Dichter MA, Reisine T (1998) Differential regulation of the cloned kappa and mu opioid receptors. Neuroscience 85:873-885.

Tang F, Costa E, Schartz J-P (1983) Increase of proenkaphalin mRNA and enkephalin content of rat striatum after daily injection of haloperidol for 2 or 3 weeks. Proc Natl Acad Sci USA 80:3841-3844.

Tarsy D, Baldessarini RJ (1984) Tardive dyskinesia. Annu Rev Med 35:605-623.

Trabucchi M, Bassi S, Frattrola L (1982) Effect of naloxone on the "on-off" syndrome in patients receiving long-term levodopa therapy. Arch Neurol 39:120-121.

Yu Y, Zhang L, Yin X, Sun H, Uhl GR, Wang JB (1997) $\mu$ opioid receptor phosphorylation, desensitization, and ligand efficacy. J Biol Chem 272:28869-28874.

Zadina JE, Hackler L, Lin-Jun G, Kastin AJ (1997) A potent and selective endogenous agonist for the $\mu$-opiate receptor. Nature 386 : 499-502. 